\title{
Chemistry in sport: context-based e-learning in chemistry
}

\author{
Nicholas M. Potter and Tina L. Overton \\ Department of Chemistry, University of Hull, Hull, HU6 7RX, UK \\ e-mail: n.m.potter@chem.hull.ac.uk, t.l.overton@hull.ac.uk
}

Received 19 February 2006, accepted 1 June 2006

\begin{abstract}
This paper details the design and use of a learning resource for independent learning in chemistry. The course presents chemistry in the context of sport and draws upon a number of models of teaching and learning, including the Perry scheme of intellectual development, multiple intelligences (MI) theory, problem/context-based learning (P/CBL), mind mapping, case studies and web-based independent learning. The resource was produced as a website containing the context, content, and the tasks to be completed as part of the assessment. Hyperlinks to additional content and external web-pages were also included. The students' response to the learning resource was positive; they enjoyed the course, found the context interesting and the presentation helpful. The assessment marks compared well with those from other modules taken by the same students in the same academic year. [Chem. Educ. Res. Pract., 2006, 7 (3), 195-202]
\end{abstract}

Keywords: Sport, chemistry in sport, chemistry in context, case-study, independent learning, web-based learning.

\section{Introduction}

A survey published recently by the English Manpower Services Commission showed that four fifths of the top $10 \%$ of British companies invested significant amounts of time and money into training (Buzan, 2003). Employers from around the world have identified the main areas requiring improvement as reading speed and comprehension, general study skills, handling the information explosion and assimilation, memory, concentration, oral and written communication skills, creative and analytical thinking, planning, note-taking, problem solving and analysis, motivation, prioritising, and time management.

Employers are now looking for graduates with a range of transferable skills (Dearing, 1995; Finer, 1996; Mason, 1998). In addition to the skills mentioned above, those of numeracy, the ability to acquire further knowledge and good interpersonal skills are desirable qualities in a graduate. However, many of these skills may be absent (Dearing, 1995, Mason, 1998). In order to facilitate a more immediately effective transition into the world of work upon graduation, students need to have acquired the skills of critical thinking and be able to tackle unfamiliar and/or open-ended problems (Belt et al., 2002). The focus of this study was to apply a number of alternative teaching and learning approaches to create a learning resource with the aim of meeting some of the aforementioned requirements.

In 'Forms of intellectual and ethical development during the college years: a scheme' Perry described nine 'positions' on the 'journey' to intellectual (and moral) development (Perry, 1970). Each level characterises the students' attitude towards knowledge, their courses of study, their teachers and their own roles in the learning process. To effect a transition through the Perry levels Knefelkamp identified the need for designing courses that will appeal to and not alienate students at various positions (Cornfield and Knefelkamp, 1979). Felder, (1997) stated that challenging students by assigning open-ended problems in context with 
marks less dependent upon the outcomes than on the process of solving the problem, especially early on in the course, will allow students to develop higher order cognitive skills, such as critical thinking.

Gardner's theory of multiple intelligences (MI) identified seven components of intelligence through anthropological, neurophysiological and cultural studies (Gardner, 1983). Gardner has encouraged alternative approaches to teaching in order to tap into and make the best use of these seven intelligences (Gardner, 1993). Kornhaber, (2001) found that MI theory reflects educators' everyday experience: students think and learn in many different ways. She says this has led many educators to develop new approaches that might better meet the needs of the range of students.

Problem- and Context-Based Learning aims to stimulate students to learn by presenting them with a real life problem that they wish to solve (Margetson, 1998). Using previously acquired knowledge, acquiring new knowledge and learning new skills, they are expected to solve the problem. Margetson stresses the value of knowledge and skills acquired in context. He also identifies the value of the learning process of inquiry, which he sees as lacking in subject-based learning where only the products of inquiry are given. Coles (1990) sees a context based approach as being effective in producing what he calls elaborated learning. Students who see the interconnections and links between different knowledge areas gained the highest scores in examinations, because they were better able to recall and use the information they had learnt.

Broadbent (1976) argues that recall is increased when the learner has multiple routes of access to the stored information. Rogers (1960) says context provides a motivating force by which the student develops a wish to know more; that is, wants rather than needs to learn something.

Context-based learning resources can be presented as problem solving case studies. According to Belt and Phipps (1998), case studies can be used to address a range of skills, develop a mode of thinking, working and communicating, and are best done by tackling openended problems. Overton (2001) states that students undertaking problem- and context-based courses show that there are many benefits to be gained from this approach. Students' motivation, attitude to study, long-term retention of knowledge, use of resources, key skills and success as postgraduates are all significantly superior when compared to students taught by conventional methods.

Hutchinson (2000) used case studies on the development of fundamental chemical concepts such as: the atomic molecular theory; the kinetic molecular theory; periodicity and valence; chemical bonding and electron pair sharing and more. Assignments and examinations throughout the course were designed to challenge the students to explain the logical connections between experimental observations and theoretical models.

Although many learning resources are made available via the web, a limited amount of research has been carried out on its effectiveness as a learning tool. Arasasingham et al. (2005) assessed large numbers of students on their understanding of stoichiometry using a web-based assessment program. With a group of students using textbooks and paper to complete the assessments as the control group, they were able to compare the web- and nonweb-based approaches. The assessment results found that the web-based students outperformed the non-web-based students and showed greater conceptual understanding. The students using the web-based course also reported that having to work independently with the program forced them to work harder on the subject, with the pay offs being instant feedback and greater understanding. Valuable feedback is often gained from the use of alternative approaches, because students have been able to appraise their course of study (usually in a positive light) and gain insight into their individual preferences, strengths and weaknesses, 
etc. They have reported enhanced understanding and retention, greater success in study, and the acquisition of new skills and knowledge.

In the past, approaches that have made use of the Perry scheme, MI theory, context/problem-based learning, mind mapping and case studies have been, on the whole, limited to paper-based courses in a classroom environment.

\section{Chemistry in Sport: the learning resource}

\section{Overview}

The learning resource developed was essentially a case study on the applications of chemistry in sport. It was designed to aid the students' acquisition of new knowledge and skills. The new knowledge included the content provided within the learning resource, the additional knowledge and skills gained by carrying out assessment tasks, information gathering using literature and the Internet; the important skills developed included critical reasoning and learning independently using alternative media e.g. the Internet.

The target students were part-time chemistry undergraduates without timetabled support for the module and with limited access to the library, so the teaching method had to be tailored to an independent learning approach. The resource provided the students with content and they were given tasks throughout. The tasks were designed to enhance understanding and extend the content already presented. Many of the tasks were open ended without a definite right or wrong answer, and the students had to support and defend their answers.

\section{Content and Context}

As sport pervades modern popular culture, it was decided to use the applications of chemistry in sport as the context. Interest in the context would be a 'way in' to the subject matter, prompting a motivation to learn on the part of the students (Rogers, 1960; Broadbent, 1976; Coles, 1990).

The learning resource comprised three sections. The first to be tackled by the students looked at the use of performance-enhancing drugs from the point of view of detection and was, therefore, primarily concerned with analytical chemistry. The students were asked to look at the cases of three British athletes who had recently been involved in drug scandals. Using these examples as case studies immediately put a familiar context and a human face on the learning resource.

In recent years, the methods employed to detect performance-enhancing drugs, and the validity of those methods, have courted as much controversy as the cases themselves. Each case, in some way, had called into question the techniques of detection, and highlighted the problems involved in the detection of performance enhancing drugs. These case studies provided a useful introduction to the concept and application of analytical chemistry (Hutchinson, 2000; Overton, 2001).

The second section looked at the three energy systems present within muscle cells and was, therefore, primarily concerned with biochemistry, focusing on the biochemical precursors to muscle movement and the ways in which athletes can legally supplement these.

The final section looked at sporting equipment, thus focusing on materials chemistry. Carbon fibre and Kevlar were identified as materials frequently used in sporting equipment, and the production, structure and application of these materials was investigated.

As a whole, the learning resource provided an insight into three aspects of applied chemistry not normally encountered at this stage of a chemistry degree course. Such a learning resource provided a built-in flexibility as each section could be used individually to supplement other areas of the chemistry curriculum. 


\section{Presentation}

The overall structure of the course was visualised using a mind mapping software called Inspiration (ver 7.5 Intl.). Mind mapping is a method of note taking and/or representing information in a non-linear, visually stimulating way (Buzan, 1991, 2003). In producing and viewing a mind map both sides of the brain are being stimulated. Such a mind map, in combination with assimilation and perception through vision, the organisation, storage and recall abilities of the brain, draws on a wide range of mental skills.

As well as text, the software could display pictures, diagrams and links between ideas and concepts. All these factors could be useful in conveying the subject matter to the students (Gardner, 1983, 1993, Kornhaber, 2001).

The Inspiration software was capable of producing an HTML document from the collection of hyperlinked mind maps. This enabled us to present the resource as a website, and content could then be linked to external websites containing relevant information for background and further reading, putting the content further into context and informing the students' learning. Using the Internet would also enable the students to develop the skill of information gathering. By using the principles of MI theory and mind mapping in a web resource, a more visual medium with which to present the course was realised (Gardner, 1993, Buzan, 1991, 2003).

The Olympic motto is "citius, altius, fortius" (faster, higher, stronger). The introductory page of the learning resource posed the question: what makes our sports stars faster, higher, stronger? (See Figure 1.) With the Olympic Games in Athens (2004) having taken place only 5 months previously, this was an event still fresh in people's minds.

\section{Results}

Before the students began the course they were asked to complete a pre-course questionnaire in order to assess the types of learning previously experienced. The pre-course questionnaire results show that, although relatively inexperienced at carrying out independent study, the students were reasonably confident about their ability to study this way. In their most recent attempt using this method
Figure 1

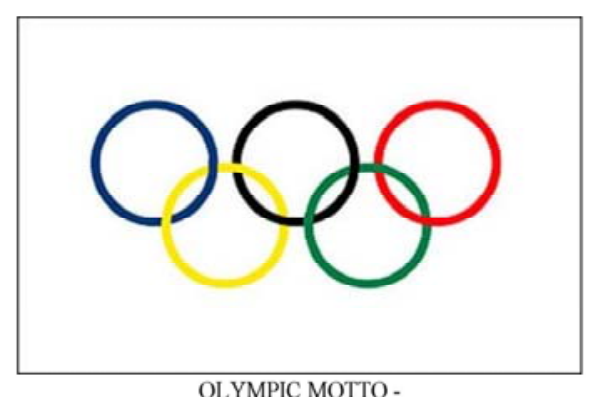

"CITTUS, ALTIUS, FORTIUS"

SO WHAT MAKES THE SPORTS STARS OF TODAY "FASTER, HIGHER, STRONGER"?
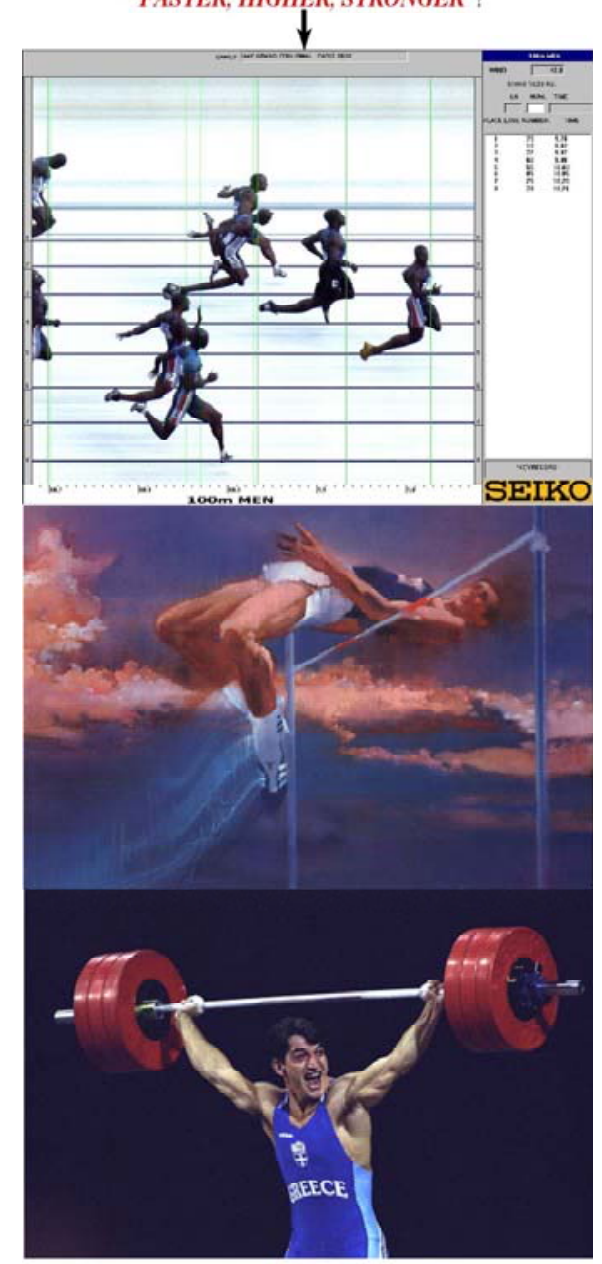
more than half of them felt they had performed averagely. They did, however, enjoy the experience. Despite only half of them having used PCs in such assignments, they were confident in working with computers and about information retrieval using the internet, but somewhat less confident using the library. The group showed a range of experiences with respect to online learning.

Figure 2. A screenshot of the introductory page.

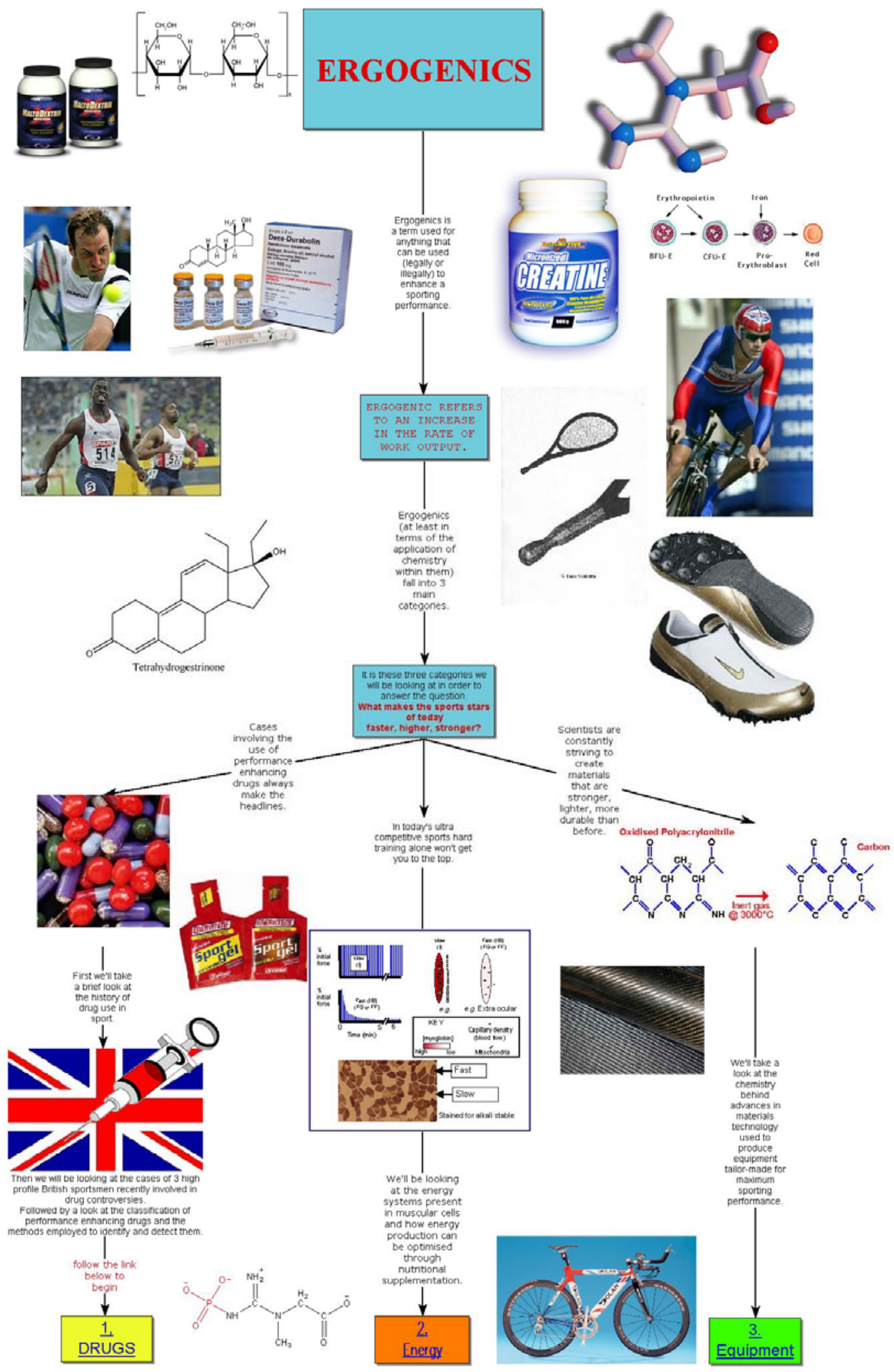

Chemistry Education Research and Practice, 2006, 7 (3), 195-202

This journal is (C) The Royal Society of Chemistry 
The students were then asked to view the learning resource via the departmental website, and complete the tasks in each section to preset deadlines. A screenshot of the introductory page is shown in Figure 2. A summary of the learning resource content and tasks can be found in Table 1.

Table 1. Resource content and task details.

\begin{tabular}{|c|c|}
\hline Content & Tasks \\
\hline $\begin{array}{l}\text { Drug use in sport, } \\
\text { case studies and history. }\end{array}$ & Choose athlete/learn case details/background reading \\
\hline $\begin{array}{l}\text { Drug use in sport, } \\
\text { nomenclature and use. }\end{array}$ & Find drug classes and effects \\
\hline \multirow{2}{*}{$\begin{array}{l}\text { Drug use in sport, } \\
\text { analytical techniques used for THG, } \\
\text { nandrolone \& EPO }\end{array}$} & Identify problems in analysis of chosen case \\
\hline & Reasons for methods of analysis \\
\hline \multirow{3}{*}{$\begin{array}{l}\text { Drug use in sport, } \\
\text { analytical instruments used for } \\
\text { THG, nandrolone \& EPO analysis } \\
\text { and associated side effects of abuse }\end{array}$} & Identification of health risks \\
\hline & Closer look at analytical techniques for chosen case \\
\hline & Closer look at problems in analysis \\
\hline $\begin{array}{l}\text { Energy systems in muscle cells of } \\
\text { humans }\end{array}$ & Background reading \\
\hline $\begin{array}{l}\text { ATP; } \\
\text { energy producing biochemical }\end{array}$ & Find chemical structure \\
\hline $\begin{array}{l}\text { ATP; } \\
\text { Energy characteristics }\end{array}$ & Find reaction and compare energy characteristics \\
\hline $\begin{array}{l}\text { Oxygen energy system; } \\
\text { aerobic glycolysis }\end{array}$ & Predict products of reaction \\
\hline $\begin{array}{l}\text { Lactic acid energy system; } \\
\text { anaerobic glycolysis }\end{array}$ & Predict products of reaction \\
\hline $\begin{array}{l}\text { Lactic acid energy system; } \\
\text { lactic acid build-up }\end{array}$ & Summarise training techniques \\
\hline \multirow{2}{*}{$\begin{array}{l}\text { ATP-CP energy system; } \\
\text { Creatine phosphate }\end{array}$} & Find purpose of chemical in energy system \\
\hline & Find and show functions of reaction \\
\hline \multirow{3}{*}{$\begin{array}{l}\text { Muscle fuel; } \\
\text { types and sources of carbohydrates } \\
\text { and electrolytes }\end{array}$} & Give examples of saccharides \\
\hline & Calculation of energy required from food \\
\hline & Calculation of molarity of a sports drink \\
\hline $\begin{array}{l}\text { Energy systems; } \\
\text { summarisation of concepts learnt in } \\
\text { this section }\end{array}$ & $\begin{array}{l}\text { Assigning energy systems to sporting events and } \\
\text { justifying answers }\end{array}$ \\
\hline Sporting equipment & Information retrieval \\
\hline $\begin{array}{l}\text { Materials chemistry; } \\
\text { synthesis and use of Kevlar and } \\
\text { carbon fibre }\end{array}$ & $\begin{array}{l}\text { Account of uses of Kevlar and carbon fibre in } \\
\text { production of materials used in sport }\end{array}$ \\
\hline
\end{tabular}




\section{Discussion}

About three weeks after handing in their assignments the students were given a postcourse questionnaire from which useful feedback was gained.

A few technical problems were encountered because of differences in operating system, software, monitor dimensions and the use of a rudimentary website design software (Inspiration). Overall the responses to the questionnaire were positive, and showed that the majority of students had been reasonably confident about carrying out the assignments, even though they felt they had performed averagely in their previous attempt at independent learning. They enjoyed the experience, found the subject matter interesting, found the presentation helpful, and retained most of the content 3-4 weeks after completing the course. They found the amount and difficulty of work neither too much nor too taxing; they thought that the learning method was effective, especially in comparison to the more traditional paperbased approach to independent learning. Some students commented on the fact that a paperbased version of the learning resource would have been more convenient, since being webbased necessitated regular and reliable internet access and not every household had these facilities, and being part-time students, they had restricted access to the on-campus PCs. The students also indicated that they would be happy to undertake a similar course of study in the future.

The students' assessment results were encouraging. The marks for the continuously assessed, year long module of which 'Chemistry in Sport' formed half, averaged $67 \%$ in the first semester and 65\% in the second semester. By comparison, the marks for the examined modules for that year for the same group of students averaged marks of 54\% and 51\%. This sort of increase in marks for a continuously assessed module is commonplace and expected, regardless of the teaching method. Since the data comes from a sample of only eight students, it cannot be seen as statistically significant but provides some indication that this was an effective approach.

Using the techniques of mind mapping, multiple intelligences (MI) theory, problem-based learning (PBL), context-based learning (CBL) and case studies seems to have enhanced the learning experience, according to the feedback from the students. Their assessed responses from this course showed that effective independent learning had occurred. Unlike the more traditional approaches used to teaching chemistry, they were given the freedom to express themselves and took the opportunity well. Being in the first year of a foundation degree course, the marks from this module will not have a large bearing on the final degree mark. Using an amalgamation of alternative teaching and learning techniques, this learning resource allowed the students the chance to make mistakes and freedom to explore how they learn without having to worry too much about the results in terms of marks. What was more important was the acquisition of new knowledge and skills that would stand them in good stead for the rest of the course and the future in general.

For the future, courses using any number of contexts could be designed in a similar format. These could include the chemistry behind everyday household items, the chemistry in food science, case studies on the development of fundamental chemical concepts, other case studies detailing the processes of discovery as well as the products and interdisciplinary approaches involving liaison with other departments. There is evidence in the literature of the effectiveness of the above techniques of MI theory, PBL, CBL and mind mapping, and such courses could make use of these. 


\section{References}

Arasasingham R.D., Taagepera M., Potter F., Martorell I. and Lonjers S., (2005), Assessing the effect of web-based learning tools on student understanding of stoichiometry using knowledge space theory, Journal of Chemical Education, 82, 1251-1261.

Belt S.T. and Phipps L.E., (1998), Using case studies to develop key skills in chemists: a preliminary account, University Chemistry Education, 2, 16-20

Belt S.T., Evans E.H., McCreedy T., Overton T.L. and Summerfield S., (2002), University Chemistry Education, 6, 65-72

Broadbent D.E., (1976), Cognitive psychology and education, British Journal of Educational Psychology, 45, 162-176.

Buzan T., (1991), Use both sides of your brain, Atlantic Books.

Buzan T., (2003), Speed reading book, BBC Books.

Coles C.R., (1990), Elaborated learning in undergraduate medical education, Medical Education, 24, 14-22.

Cornfield J.L. and Knefelkamp L.L., (1979), Combining a student stage and type in the designing of learning environments: an integration of Perry stages and Holland typologies, Paper presented at the American college personnel association, Los Angeles.

Dearing R., (1995), Skills for graduates in the 21st century, the Association of Graduate Employers, Cambridge.

Felder, R.M., (1997), Meet your students 7, Dave, Martha, and Roberto. Chemical Engineering Education, 31, 106-107.

Finer E., (1996), Chemistry in Britain, 32 (10), 3.

Gardner H., (1983), Frames of mind: the theory of multiple intelligences, Basic Books, New York.

Gardner H., (1993), Multiple intelligences: the theory in practice, Basic Books, New York.

Hutchinson J.S., (2000), Teaching introductory chemistry using concept development case studies: interactive and inductive learning, University Chemistry Education, 4, 3-9.

Kornhaber M.L., (2001), 'Howard Gardner' in J. A. Palmer (ed.) Fifty modern thinkers on education. From Piaget to the present, Routledge, London.

Margetson D., (1998), Why is problem-based learning a challenge? in The challenge of problem-based learning / ed. by D. Boud and G.I. Feletti, Imprint ,London, Kogan Page.

Mason G., (1998), Change and diversity: the challenges facing higher education, Royal Society of Chemistry.

Overton T.L., (2001), Problem based learning: an introduction, LTSN Physical Sciences Primer 4, version 1.

Perry W.G. Jr., (1970), Forms of intellectual and ethical development in the college years: a scheme, New York, Holt, Rinehart, and Winston.

Rogers C.R., (1960), On becoming a person, Constable, London. 